\title{
Water Resource, Hygienic Practice, and Soil Transmitted Helminthiasis in Some Rural Communities of Osun State, Nigeria
}

\author{
Toluwani Sunday Fafunwa1, Hammed Oladeji Mogaji1,2, Akinola Stephen Oluwole1, \\ Abdulhakeem Adebiyi Adeniran', Mariam Tobi Fagbenro', Sammy Olufemi Sam-Wobo1, \\ Babatunde Saheed Bada ${ }^{3}$, Uwem Friday Ekpo ${ }^{1}$
}

\author{
${ }^{1}$ Department of Pure and Applied Zoology, Federal University of Agriculture, Abeokuta, Nigeria \\ ${ }^{2}$ Department of Animal and Environmental Biology, Federal University Oye-Ekiti, Oye-Ekiti, Nigeria \\ ${ }^{3}$ Department of Environmental Management and Toxicology, Federal University of Agriculture, Abeokuta, Nigeria \\ Email: mogajihammed@gmail.com
}

How to cite this paper: Fafunwa, T.S.,
Mogaji, H.O., Oluwole, A.S., Adeniran, A.A.,
Fagbenro, M.T., Sam-Wobo, S.O., Bada,
B.S. and Ekpo, U.F. (2017) Water Resource,
Hygienic Practice, and Soil Transmitted
Helminthiasis in Some Rural Communities
of Osun State, Nigeria. Journal of Water
Resource and Protection, 9, 99-110.
https://doi.org/10.4236/jwarp.2017.92008

Received: November 21, 2016

Accepted: February 1, 2017

Published: February 4, 2017

Copyright $\odot 2017$ by authors and Scientific Research Publishing Inc. This work is licensed under the Creative Commons Attribution International License (CC BY 4.0).

http://creativecommons.org/licenses/by/4.0/ (c) (i) Open Access

\begin{abstract}
Provision of water, sanitation and hygiene (WASH) resources has been advocated as necessary add-on strategy for sustainable control of soil-transmitted helminthiasis (STH) alongside annual mass drug administration (MDA) of albendazole to endemic communities. This study investigated the burden of STH and status of WASH resources in eight rural communities in Aiyedaade LGA, Osun State, Nigeria. Four of the communities were supported with improved water and hygiene resources (Category A), and another four supported only with improved water resources (Category B). Two hundred and sixteen (216) fresh stool samples were collected from consenting community members and screened for Ascaris lumbricoides, Hookworm and Trichuris trichiura infections using ether concentration method. The status and condition of WASH resources were determined using questionnaire and physical observation. An overall prevalence of 35.2\% was observed for any STH infection. Species' prevalence of Ascaris lumbricoides, Hookworm and Trichuris trichiura prevalence was $33.8 \%, 22.7 \%$, and $0.5 \%$ respectively. Intensity of STH infection was significantly higher in Category A communities than in Category B communities. The prevalence of STH in Category A communities was higher $(42.0 \%)$ than that in Category B communities (30.1\%). There were significant differences $(p=0.000)$ in STH infections between the two categories. The status of improved water supply was not significantly different $(p=$ 0.3153 ) in the two categories. Knowledge, attitude, and practices about STH, its transmission and control were low in both categories of communities. These results imply that current implementation of WASH which tends to focus on resource distribution, equity, and coverage, is unlikely to impact on STH transmission and control. Therefore, it is necessary for WASH providers to consider STH transmission control in their planning and implementation
\end{abstract}


of WASH intervention for STH endemic communities.

\section{Keywords}

Water, Sanitation, Hygiene, Soil Transmitted Helminthiasis, Osun State, Nigeria

\section{Introduction}

Soil-Transmitted Helminths (STH) infections affect more than 2 billion people worldwide, with the greatest indices in sub-Saharan Africa, Americas, China and East-Asia [1] [2] [3] [4]. Four species of worms cause most infection: Ascaris lumbricoides, Trichuris trichiura, Ancylostoma duodenale and Necator americanus [5]. These groups of worms are not uncommon in rural developing countries, usually because their transmission cycle requires the existing adequate soil moisture and warm temperature for larval development [6] [7] [8]. Other exacerbating factors that aid the development of their eggs and transmission of infective larva to susceptible hosts include lack of water supply source, sanitation, and poor personal hygiene especially shoe wearing and hand washing [7] [9].

Preventive chemotherapy (i.e. the periodic large-scale administration of anthelmintic drugs to at-risk populations without prior diagnosis) has been employed in the control of this disease, but there has been remarkable rise in reinfection patterns after treatment is stopped [10]. Providing access to improved Water, Sanitation, and Hygiene (WASH) resource has therefore gained traction as the world tries to eliminate the disease by 2020 .

WASH resources programming includes providing access to safe water, improved sanitation and good hygiene practices and education. Implementation of WASH continues to gain momentum with increased commitment from governmental and non-governmental donors through the provision of funds and resources [11]. For instance, Nigeria has benefited substantially from UNICEF's assisted WASH resources either community-based or school-based due to poor safe water and sanitation coverage rates in the country [11]. There is a standing belief that access to improved WASH resources coupled with preventive chemotherapy would have a long-term educational impact on the development and transmission of STH in endemic areas [12].

Although, the findings of Ekpo et al. (2008) in Ogun State, Nigeria have highlighted the relationship between helminthiasis and hygiene practices in school children [13]. There is an urgent need to provide evidence, if any, on the impact of current provision of community-based WASH resources on the transmission and control of STHs.

\section{Methodology}

\subsection{Study Area}

The study was conducted in Aiyedaade LGA, Osun state in South-western Nigeria (Figure 1). The LGA is supported by UNICEF in the provision of WASH 


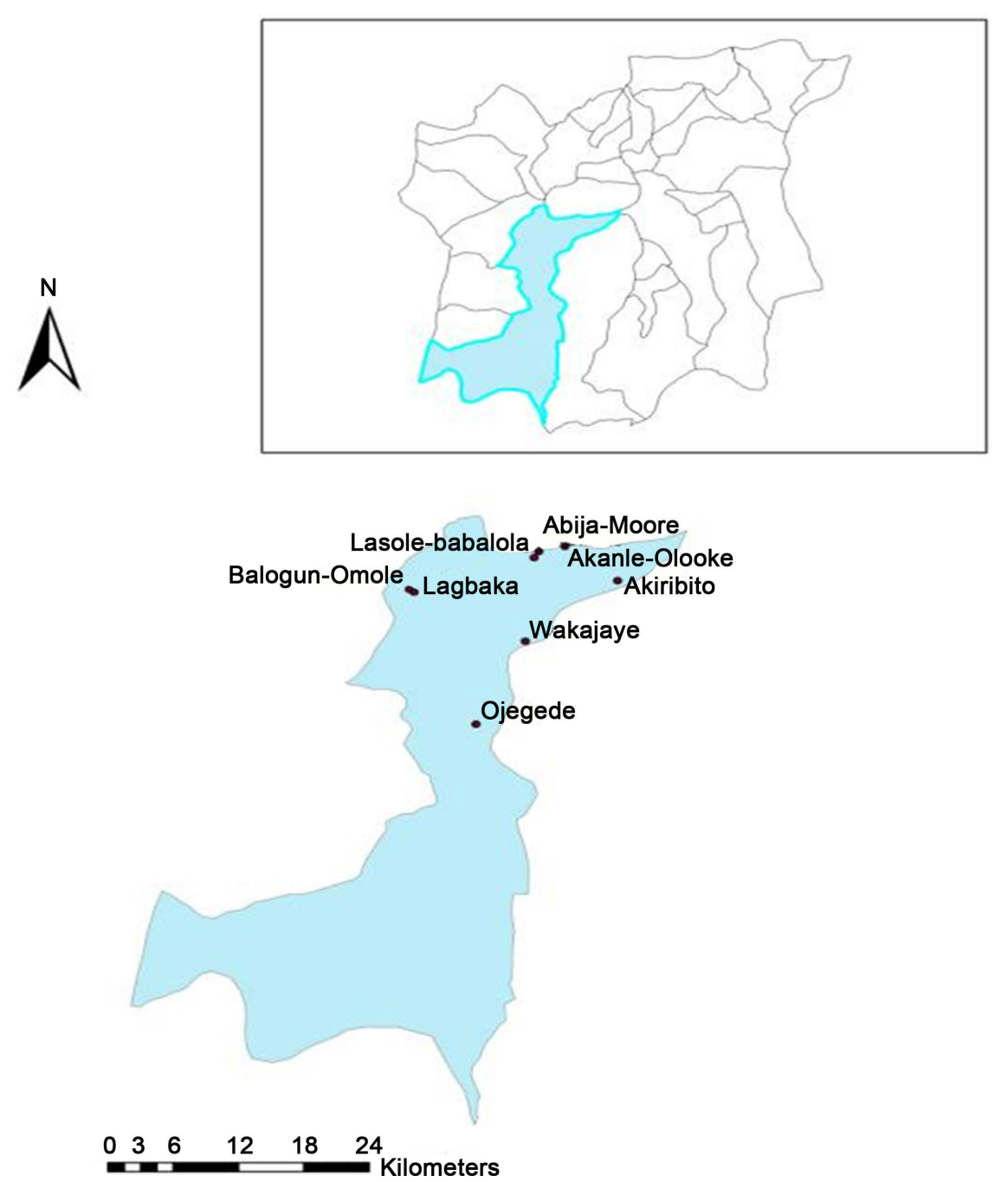

Figure 1. Map of Aiyedaade LGA showing the study communities with Osun state as insert.

resources at schools and communities. These include provision of safe water supply, behavioural change promotional activities and community resource management planning for improved sanitation. The provided WASH resources was neither targeted at STH transmission control nor complimentary to MDA, but solely of equity, coverage, and prevention of water borne diseases, most especially diarrhoea.

Of the 329 communities in this LGA, fourteen were supported by UNICEF with provision of safe water supply source, behavioural change promotional activities and community resource management planning for improved sanitation (Category A-Full WASH). Whereas, twelve other communities were supported by UNICEF with only provision of safe water supply (Category B-Partial WASH). There was no direct provision of improved sanitation facilities in the study area. However, community members are being encouraged to construct toilets using local resources within their reach at community management planning meetings. 


\subsection{Sampling Procedures}

Purposeful sampling was employed in the selection of 8 communities based on their level of WASH support (Table 1). Category A communities had full WASH implementation and includes; Lasole-babalola, Akanle-olooke, Abija-moore, and Wakajaye, while communities in Category B with partial WASH implementation were Ojegede, Akiribito, Lagbaka, and Balogun-omole. A complete census of the selected communities was then carried out to calculate the required sample size. The total population of the community was used for the determination of the required sample size using the method of Yamane [14].

\subsection{Ethics Statement}

Ethical clearance for the study was obtained from the Federal University of Agriculture; Abeokuta ethics review board and Osun State Ministry of Health. Permit to use the selected communities for sample collections were obtained from Aiyedaade LGA Primary Healthcare Centre. Pre-survey contact/advocacy meetings were also made to the community heads as well as the community members to ensure their support and co-operation. Written/verbal informed consent was obtained from coomunity leaders, parents, and guardians prior the conduct of the study.

Table 1. Demography of the study participants.

\begin{tabular}{|c|c|c|c|c|c|c|c|c|c|c|}
\hline & & & $\begin{array}{l}\text { Category } \\
\text { with full }\end{array}$ & $\begin{array}{l}\text { A: Communiti } \\
\text { mplementatio }\end{array}$ & & & $\begin{array}{l}\text { Category B: } \\
\text { ith partial i }\end{array}$ & $\begin{array}{l}\text { Communiti } \\
\text { iplementat }\end{array}$ & & \\
\hline & & $\begin{array}{c}\text { Lasole- } \\
\text { babalola }\end{array}$ & $\begin{array}{c}\text { Akanle- } \\
\text { olooke }\end{array}$ & Abija-moore & Wakajaye & Ojegede & Akiriboto & Lagbaka & $\begin{array}{c}\text { Balogun- } \\
\text { omole }\end{array}$ & Total \\
\hline & & NE (\%) & NE (\%) & NE (\%) & NE (\%) & NE (\%) & NE (\%) & NE (\%) & NE (\%) & NE (\%) \\
\hline & $\leq 4$ & $4(20.0)$ & $0(0.0)$ & $1(5.0)$ & $7(35.0)$ & $0(0)$ & $3(15.0)$ & $3(15.0)$ & $2(10.0)$ & $20(9.3)$ \\
\hline & $5-14$ & $7(25.9)$ & $1(3.7)$ & $6(22.2)$ & $1(3.7)$ & $0(0)$ & $3(11.1)$ & $8(29.6)$ & $1(3.7)$ & $27(12.5)$ \\
\hline Age group & $15-24$ & $5(26.3)$ & $1(5.3)$ & $1(5.3)$ & $5(26.3)$ & $3(15.8)$ & $4(21.1)$ & $0(0.0)$ & $0(0.0)$ & $19(8.8)$ \\
\hline & $25-34$ & $6(17.1)$ & $4(11.4)$ & $1(2.9)$ & $4(11.4)$ & $2(5.7)$ & $6(17.1)$ & $10(28.6)$ & $2(5.7)$ & $35(16.2)$ \\
\hline & $35-44$ & $2(6.7)$ & $1(3.3)$ & $3(10.0)$ & $4(13.3)$ & $3(10.0)$ & $5(16.7)$ & $6(20.0)$ & $6(20.0)$ & 30 (13.9) \\
\hline & $45-54$ & $1(4.8)$ & $2(9.5)$ & $2(9.5)$ & $1(4.8)$ & $0(0.0)$ & $8(38.1)$ & $4(19.0)$ & $3(14.3)$ & $21(9.7)$ \\
\hline & $\geq 55$ & $7(10.9)$ & $5(7.8)$ & $0(0.0)$ & $11(17.2)$ & $3(4.7)$ & $23(35.9)$ & $9(14.1)$ & $6(9.4)$ & $64(29.6)$ \\
\hline & Total & $32(14.8)$ & $14(6.5)$ & $14(6.5)$ & $33(15.3)$ & $11(5.1)$ & $52(24.1)$ & $40(18.5)$ & $20(9.3)$ & $216(100.0)$ \\
\hline & Female & $15(14.5)$ & $10(8.1)$ & $5(4.0)$ & $19(15.3)$ & $6(4.8)$ & $31(25.0)$ & $21(16.9)$ & $14(11.3)$ & $124(57.4)$ \\
\hline Sex & Male & $17(18.4)$ & $4(4.3)$ & $9(9.7)$ & $14(15.2)$ & $5(5.4)$ & $21(22.8)$ & $19(20.7)$ & $6(6.5)$ & $92(42.6)$ \\
\hline & Total & $32(14.8)$ & $14(6.5)$ & $14(6.5)$ & $33(15.3)$ & $11(5.1)$ & $52(24.1)$ & 40 (18.5) & $20(9.3)$ & $216(100.0)$ \\
\hline & None & $10(11.8)$ & $8(9.4)$ & $5(5.9)$ & $12(14.1)$ & $5(5.9)$ & $24(28.2)$ & $11(12.9)$ & $10(11.8)$ & $85(39.4)$ \\
\hline Educational & Primary & $13(18.3)$ & $3(4.2)$ & $6(8.5)$ & 15 (21.1) & $5(7.0)$ & $7(9.9)$ & $18(25.4)$ & $4(5.6)$ & $71(32.9)$ \\
\hline attainment & Secondary & $8(15.1)$ & $3(5.7)$ & $3(5.7)$ & $5(9.4)$ & $1(1.9)$ & $17(32.1)$ & $10(18.9)$ & $6(11.3)$ & $53(24.5)$ \\
\hline status & Tertiary & $1(14.3)$ & $0(0.0)$ & $0(0.0)$ & $1(14.3)$ & $0(0.0)$ & $4(57.1)$ & $1(14.3)$ & $0(0.0)$ & $7(3.2)$ \\
\hline & Total & $32(14.8)$ & $14(6.5)$ & $14(6.5)$ & $33(15.3)$ & $11(5.1)$ & $52(24.1)$ & 40(18.5) & $20(9.3)$ & $216(100.0)$ \\
\hline
\end{tabular}

NE: Number examined. 


\subsection{Data Collection}

Data were collected using two different field forms. The demographics (name, date of birth, age, sex, educational attainment) and the Knowledge, Attitude, and Practices (KAP) were collected using the first field form. Another form was used to assess the status and conditions of WASH resources at the community level. These include the type and condition of water supply source.

\subsection{Determination of STH Burden}

A single stool sample was collected from each consenting community member, processed within two hours using Sodium acetate-acetic acid formalin concentration method (SAF-Ether) and examined for intestinal ova of STH. STH eggs were counted for each species observed, and the mean number of egg per one gram (EPG) of stool was recorded for each community to compute infection intensities.

\subsection{Scoring of Status and Condition of Water Supply}

The type, conditions, adequacy, and usage of water resource were assessed using a WHO/UNICEF recommended checklist for improved WASH interventions. The status and condition of the WASH resources were carefully observed during field visitations and those that met the WHO/UNICEF set standards (i.e. improved conditions) were scored one point, while those not meeting the set standards were scored a negative point as appropriate. A cumulative test score was computed and used for comparison using chi-square statistics.

\subsection{Data Analysis}

Descriptive statistics were used to describe the characteristics of the study population. The number of egg per gram of stool were transformed using $\log (n+1)$ of raw count. The differences in prevalence and intensity of STH infections between the community category were determined using chi-square statistics, $\mathrm{t}$-test and analysis of variance respectively. Significances were set at $p \leq 0.05$.

\section{Results}

\subsection{Demography of Study Participants}

Of the 216 participants, 124 (57.4\%) were females and 92 (42.6\%) were males. By age category, participantsaged 55 years were $29.6 \%$ of the total study population. There were no significant differences $(p=0.579)$ in sex distribution, unlike ( $p=$ $0.002)$ in age distribution among the study participants. By educational attainment status, 85 (39.4\%) of the participants were not learned, 71 (32.9\%) had primary education while $53(24.5 \%)$ and 7 (3.2\%) had secondary and tertiary education respectively. However, there exist no significant difference in educational attainment status across the participants $(p=0.201)$ (Table 1$)$.

\subsection{Status of Water Supply across the Surveyed Communities}

There were similarities in the sources of water and their conditions in the two 
categories of communities. All communities had hand-pump boreholes as their source of water supply. In Lasole-babalola and Akiriboto communities there are protected dug wells in addition to the hand-pump borehole. However, in LasoleBabalolathe hand-pump borehole in the community produces undrinkable water. A cumulative score of 11 (91.6\%) for safe water supply and conditions was recorded for Category A, while a cumulative score of $12(100.0 \%)$ was recorded for communities in Category B. There was no significant difference $(p=0.3153)$ in safe water supply between the two group of communities (Table 2).

\subsection{Prevalence of Soil Transmitted Helminths (STH) Infection}

A total of $76(35.2 \%)$ of 216 participants examined were infected with at least a species of any STH. Species prevalence for Ascaris lumbricoides, hookworms, and Trichuris trichiura was $33.8 \%, 22.7 \%$, and $0.5 \%$ respectively. Comparison of STH prevalence between the two categories of communities shows a prevalence of $42.0 \%$ in Category A compared to $30.1 \%$ in Category B. There was a significant difference in STH prevalence between the two categories $(p=0.001)$ (Table 3).

\subsection{Intensity of Soil Transmitted Helminths (STHs) Infection}

Ascaris lumbricoides infection intensities were the highest of all the STHs recorded. The intensity of Ascaris lumbricoides infection for Category Acommunities $(103.31 \pm 30.33 \mathrm{epg})$ was significantly higher $(p=0.011)$ when compared to intensity of infection for Category Bcommunities (50.60 $\pm 17.283 \mathrm{epg})$. Likewise, there was a significant difference $(p=0.021)$ in the intensities of $T$. trichuria infection which was higher in Category A communities $(0.11 \pm 0.108 \mathrm{epg})$

Table 2. Status of water supply across the surveyed communities.

\begin{tabular}{|c|c|c|c|c|}
\hline & $\begin{array}{l}\text { Water source } \\
\text { (test-score) }\end{array}$ & $\begin{array}{l}\text { Condition of water } \\
\text { source (test-score) }\end{array}$ & $\begin{array}{l}\text { Supply of water } \\
\text { (test-score) }\end{array}$ & $\begin{array}{c}\text { Cummulative } \\
\text { test score }\end{array}$ \\
\hline \multicolumn{5}{|c|}{ Communities with full implementation } \\
\hline Lasole-babalola & Protected Dug well and Hand-pump borehole (1.0) & Functioning and Dirty $(-1.0)$ & Daily (1.0) & 2.0 \\
\hline Akanle-Olooke & Hand-pump borehole (1.0) & Functioning and Clean (1.0) & Daily (1.0) & 3.0 \\
\hline Abija-moore & Hand-pump borehole (1.0) & Functioning and Clean (1.0) & Daily (1.0) & 3.0 \\
\hline Wakajaye & Hand-pump borehole (1.0) & Functioning and Clean (1.0) & Daily (1.0) & 3.0 \\
\hline Total & 4.0 & 3.0 & 4.0 & $11.0(91.6 \%)$ \\
\hline \multicolumn{5}{|c|}{ Communities with part implementation } \\
\hline Ojegede & Hand-pump borehole (1.0) & Functioning and Clean (1.0) & Daily (1.0) & 3.0 \\
\hline Akiriboto & Hand-pump borehole andProtected dug well (1.0) & Functioning and Clean (1.0) & Daily (1.0) & 3.0 \\
\hline Lagbaka & Hand-pump borehole (1.0) & Functioning and Clean (1.0) & Daily (1.0) & 3.0 \\
\hline Balogunomole & Hand-pump borehole (1.0) & Functioning and Clean (1.0) & Daily (1.0) & 3.0 \\
\hline Total & 4.0 & 4.0 & 4.0 & $12.0(100 \%)$ \\
\hline
\end{tabular}

$p$-value $=0.3153$ 
Table 3. Prevalence of Soil Transmitted Helminths (STH) infection.

\begin{tabular}{|c|c|c|c|c|c|}
\hline & \multirow{2}{*}{$\mathrm{NE}$} & \multirow{2}{*}{$\begin{array}{c}\text { Ascaris lumbricoides } \\
\text { NI (\%) }\end{array}$} & \multirow{2}{*}{$\begin{array}{c}\text { Trichuris trichiura } \\
\text { NI (\%) }\end{array}$} & \multirow{2}{*}{$\begin{array}{c}\text { Hookworm } \\
\text { NI (\%) }\end{array}$} & \multirow{2}{*}{$\begin{array}{c}\text { Any STH } \\
\text { NI (\%) }\end{array}$} \\
\hline & & & & & \\
\hline \multicolumn{6}{|c|}{$\begin{array}{l}\text { Category A-Communities } \\
\text { with full implementation }\end{array}$} \\
\hline LasoleBabalola & 32 & $13(40.6)$ & $0(0.0)$ & $12(37.5)$ & $9(59.4)$ \\
\hline AkanleOlooke & 14 & $6(42.9)$ & $1(7.1)$ & $3(21.4)$ & $6(42.9)$ \\
\hline Abija Moore & 14 & $11(78.6)$ & $0(0.0)$ & $8(57.1)$ & $11(78.6)$ \\
\hline Wakajaye & 33 & $12(36.4)$ & $0(0.0)$ & $8(24.2)$ & $13(39.4)$ \\
\hline Total & 93 & $42(45.2)$ & $1(1.1)$ & $31(33.3)$ & $39(42.0)$ \\
\hline \multicolumn{6}{|c|}{$\begin{array}{l}\text { Category B-Communities } \\
\text { with Part implementation }\end{array}$} \\
\hline Ojegede & 11 & $2(18.2)$ & $0(0.0)$ & $2(18.2)$ & $2(18.2)$ \\
\hline Akiriboto & 52 & $9(17.3)$ & $0(0.0)$ & $5(9.6)$ & $12(23.1)$ \\
\hline Lagbaka & 40 & $12(30.0)$ & $0(0.0)$ & $5(12.5)$ & $12(30.0)$ \\
\hline BalogunOmole & 20 & $8(40.0)$ & $0(0.0)$ & $6(30.0)$ & $11(55.0)$ \\
\hline Total & 123 & $31(25.2)$ & $0(0.0)$ & $18(14.6)$ & $37(30.1)$ \\
\hline Overall NE & 216 & $73(33.8)$ & $1(0.5)$ & $49(22.7)$ & $76(35.2)$ \\
\hline$P$-value & & 0.003 & 0.043 & 0.003 & 0.001 \\
\hline
\end{tabular}

$\mathrm{NE}=$ Number examined, $\mathrm{NI}=$ Number infected.

compared to Category B communities $(0.00 \pm 0.00 \mathrm{epg})$. However, there was no significant difference $(p=0.354)$ in the intensity of Hookworms infection in Category A $(13.87 \pm 4.983 \mathrm{epg})$ compared to Category B $(8.87 \pm 3.678 \mathrm{epg})$ (Table 4).

\subsection{Survey on Knowledge, Hygiene Attitude, and Practices}

Knowledge about how STH is been transmitted was poor and not significantly different $(p=0.027)$ among members in both categories of community (Table 5). For category A, 83(41.1\%) and 85 (41.7\%) of the community members were unable to link human faeces and dirty water with STH transmission respectively. Likewise, in Category B there were 119 (58.9\%) and 119 (58.3\%) community members who could not link human faeces and dirty water with STH transmission respectively. Defecation inside the bush was a common practice for community members in Category B compared to members in Category A (98 $(76.6 \%)$ vs $25(28.4 \%)$ respectively. There was a significant difference $(p=0.000)$ in the defecation methods between the community groups. Other hygienic practices that could prevent STH transmission such as cutting of nails and wearing of footwear was not common in both category of communities. $56.2 \%$ and $56.9 \%$ of community members in Category B neither cut nails nor wear sandal regularly, as compared to $43.8 \%$ and $43.1 \%$ respondents from communities in Category A respectively (Table 5). 
Table 4. Intensity of soil-transmitted Helminths.

\begin{tabular}{cccc}
\hline & $\begin{array}{c}\text { Category A: Communities } \\
\text { with full implementation }\end{array}$ & $\begin{array}{c}\text { Category B: Communities } \\
\text { with part implementation }\end{array}$ & Mean Log EPG \\
\cline { 2 - 4 } Mean Log EPG & $103.31 \pm 30.33$ & $50.60 \pm 17.283$ & 0.011 \\
Hookworis lumbricoides & $13.87 \pm 4.983$ & $8.87 \pm 3.678$ & 0.354 \\
Trichuris trichiura & $0.11 \pm 0.108$ & $0.00 \pm 0.00$ & 0.021 \\
\hline
\end{tabular}

$E P G=$ Egg Per gram.

Table 5. Survey on knowledge, hygiene, attitude, and practices.

\begin{tabular}{|c|c|c|c|c|c|}
\hline & & NE (\%) & $\begin{array}{l}\text { Category A: Communities } \\
\text { benefitting from water provision } \\
\text { and hygiene educational } \\
\text { activity support NE (\%) }\end{array}$ & $\begin{array}{c}\text { Category B: Communities } \\
\text { benefitting only from } \\
\text { water provision support NE (\%) }\end{array}$ & $p$ value \\
\hline \multirow{2}{*}{ Have you heard of WASH } & Yes & $23(10.6)$ & $16(69.6)$ & $7(30.4)$ & 0.007 \\
\hline & No & $193(89.4)$ & $77(39.9)$ & $116(60.1)$ & \\
\hline \multirow{2}{*}{$\begin{array}{c}\text { Knows faeces } \\
\text { can contain worms }\end{array}$} & Yes & $14(6.5)$ & $10(71.4)$ & $4(28.6)$ & 0.027 \\
\hline & No & $202(93.5)$ & $83(41.1)$ & $119(58.9)$ & \\
\hline \multirow{2}{*}{$\begin{array}{c}\text { Knows one can get } \\
\text { worms from dirty water }\end{array}$} & Yes & $12(5.6)$ & $8(66.7)$ & $4(33.3)$ & 0.089 \\
\hline & No & $204(94.4)$ & 85 (41.7) & $119(58.3)$ & \\
\hline \multirow{2}{*}{ Where do you defecate } & Bush & $128(59.3)$ & $30(23.4)$ & $98(76.6)$ & 0.000 \\
\hline & Toilet & 88 (40.7) & $63(71.6)$ & $25(28.4)$ & \\
\hline \multirow{3}{*}{$\begin{array}{l}\text { What do you use } \\
\text { for anal cleaning }\end{array}$} & Leaf & $17(7.9)$ & $14(82.4)$ & $3(17.6)$ & 0.002 \\
\hline & Water & $198(91.7)$ & 79 (39.9) & $119(60.1)$ & \\
\hline & Paper & $1(0.5)$ & $0(0.0)$ & $1(100.0)$ & \\
\hline \multirow{2}{*}{$\begin{array}{l}\text { Presence of clean } \\
\quad \text { fingernails }\end{array}$} & Yes & $13(6.0)$ & $4(30.8)$ & $9(69.2)$ & 0.356 \\
\hline & No & $203(94.0)$ & $89(43.8)$ & $114(56.2)$ & \\
\hline \multirow{2}{*}{$\begin{array}{l}\text { Presence of } \\
\text { footwear }\end{array}$} & Yes & $107(49.5)$ & $46(43.0)$ & $61(57.0)$ & 0.985 \\
\hline & No & $109(50.5)$ & $47(43.1)$ & $62(56.9)$ & \\
\hline \multirow{2}{*}{$\begin{array}{l}\text { Do you wash your } \\
\text { hands after toilet use }\end{array}$} & Yes & $202(93.5)$ & 79 (39.1) & $123(60.9)$ & 0.000 \\
\hline & No & $14(6.5)$ & $14(100.0)$ & $0(0.0)$ & \\
\hline \multirow[t]{3}{*}{ What do you use for hand-washing } & Water & $128(58.3)$ & $31(24.6)$ & $95(75.4)$ & 0.000 \\
\hline & Soap & $88(40.7)$ & $60(68.2)$ & $28(31.8)$ & \\
\hline & Ash & $2(0.9)$ & $2(100.0)$ & $0(0.0)$ & \\
\hline
\end{tabular}

\section{Discussion}

This study presents for the first time the conditions and status of UNICEF supported community-based WASH resources, and its possible impact on the transmission and control of STH infections in the study area. An overall prevalence of $35.2 \%$ was recorded for any STH infection. This prevalence is higher than that reported for Ile-ife, Osun State [15], and reflects the worrisome burden 
of STH in the communities surveyed. This observation calls for mass administration of albendazole by WHO prevalence cut-off recommendations [16]. Non-school aged population should not be excluded from any treatment activity, as neglecting them can be a source for community re-infection especially in the case of Hookworm infection [17].

Unexpectedly, higher prevalence and intensities of STH were recorded in Category A communities (benefitting from a fully implemented WASH programme), and this issues a call of concern. It is expected that areas benefitting from WASH resource programming should have lower prevalence and intensity, in comparison with areas where intervention is either not on-going or partly implemented. However, our results show provision of WASH resources in these communities may have minimal impact on STH transmission.

There are several explanations to this. First, programming for WASH improvement in low- and middle-income countries is aimed at increasing equitable access to clean water, adequate sanitation, especially at the unit of the household, and improved hygiene education to people living in poor rural and deprived urban settings [11]. In actual terms, WASH programming have not been directed towards STH prevention or control, although there is a secondary influence of WASH resources on STH [18]. It is, therefore, understandable that implementation of this programme in Aiyedade LGA might be sub-optimal to trigger reduction of STH infection. This study did not conduct an in-depth evaluation survey for the WASH intervention in the areas visited. This is a research gap. There is need to understand further the thresholds that exist for each WASH resource component to trigger STH prevention or control.

On a second note, higher prevalence and intensities of STH in Category A communities may be an indication that the hygiene component of WASH resources has not resulted in any significant hygiene behaviour that could help reduce transmission of STH infection. This is more so as community members' knowledge of STH transmission was very low in these communities. Hygiene education if properly embraced by community members could help in reducing helminth infection by creating an enabling environment for both effective chemotherapy and sanitation efforts [19] [20], but non-compliance to the dictates of an hygiene education would cause continuous re-infection [20]. This observation, therefore, call into question the effeciveness of behavioural change promotional activities implemented in Category A communities, and if they were targeted at breaking STH transmission cycle?

It is also important to take into consideration that there was no support for provision of improved sanitation facilities in the study area. Providing toilet infrastructure would require huge cost and community involvements. However, in place of providing toilet infrastructure, communities are usually being encouraged during community planning meetings to mobilize local resources in the construction of latrines that would prevent direct exposure to faecal materials. Since there is no support for toilet resource, community member usually defecates in open grounds or nearby bushes [21]. This observation might be a prob- 
able reason for the continued contamination of soil, thus promoting STH reinfection, even when water resource and hygiene education programmes are in place.

Other reasons for the disparities in prevalence between both categories of communities could be related to educational attainment status, standard of personal and environmental hygiene and probably social habits [22]. Our findings shows that knowledge, attitude, and practices associated with STH transmission between communities with full and part implementation of WASH intervention was poor. Although members of communities with full implementation recorded higher knowledge, attitude, and practices as compared with communities with part implementation, nevertheless it was still poor. These overall poor knowledge, attitude and practices have been implicated as factors that promotes contamination of soil with eggs and as well transmission of infective stages of the nematodes to humans [23]. There is need to reemphasize on strategies of harmonizing health-educational tools given improving hygienic behaviours and attitudes of people living in areas where STH are endemic [10] [24].

\section{Conclusion}

Our study demonstrates that current strategy of UNICEF supported WASH programming focusing on equity and coverage may not necessarily compliment STH transmission control in benefiting STH endemic communities unless WASH providers review this strategy. However, this will require synergies between WASH providers and STH disease control managers in the planning and implementation of WASH resources in STH endemic communities.

\section{References}

[1] World Health Organization (2006) Preventive Chemotherapy in Human Helminthiasis: Coordinated Use of Anthelminthic Drugs in Control Interventions: A Manual for Health Professionals and Programme Managers. World Health Organization Press, Geneva, 63.

[2] Hotez, P.J., Asojo, O.A. and Adesina, A.M (2012) Nigeria: "Ground Zero" for the High Prevalence of Neglected Tropical Diseases. PLoS Neglected Tropical Diseases, 6, e1600. https://doi.org/10.1371/journal.pntd.0001600

[3] Brooker, S., Clements, A.C.A. and Bundy, D.A.P. (2006) Global Epidemiology, Ecology, and Control of Soil-Transmitted Helminth Infections. Advances in Parasitology, 62, 221-261. https://doi.org/10.1016/S0065-308X(05)62007-6

[4] Pullan, R.L., Smith, J.L., Jasrasaria, R. and Brooker, S.J. (2014) Global Numbers of Infection and Disease Burden of Soil Transmitted Helminth Infections in 2010. Parasites and Vectors, 7, 37. https://doi.org/10.1186/1756-3305-7-37

[5] Tchuem Tchuenté, L.A. (2011) Control of Soil-Transmitted Helminths in SubSaharan Africa: Diagnosis, Drug Efficacy Concerns, and Challenges. Acta Tropica, 120, 4-11. https://doi.org/10.1016/j.actatropica.2010.07.001

[6] Brooker, S. and Michael, E. (2000) The Potential of Geographical Information Systems and Remote Sensing in the Epidemiology and Control of Human Helminth Infections. Advances in Parasitology, 47, 245-288. https://doi.org/10.1016/S0065-308X(00)47011-9 
[7] de Silva, N.R., Brooker, S., Hotez, P.J., Montresor, A., Engels, D. and Sarioli, L. (2003) Soil-Transmitted Helminth Infections: Updating the Global Picture. Trends in Parasitology, 19, 547-551. https://doi.org/10.1016/j.pt.2003.10.002

[8] Babatunde, S.K., Adedayo, M.R., Ajiboye, A.E., Sunday, O. and Ameen, N. (2013) Soil-Transmitted Helminth Infection among School Children in Rural Communities of Moro Local Government Area, Kwara State, Nigeria. African Journal of Microbiology Research, 7, 5148-5153. https://doi.org/10.5897/AJMR2013.6258

[9] Ijagbone, I.F. and Olagunju, T.F. (2006) Intestinal Helminth Parasites in School Children in Iragbiji, Boripe Local Government, Osun State, Nigeria. African Journal of Biomedical Research, 9, 63-66.

[10] Jia, T.W., Mellelhe, S., Utzinger, J., King, C.H. and Zhou, X.N. (2012) Soil Transmitted Helminth Re-Infection after Drug Treatment: A Systematic Review and Meta-Analysis. PLoS Neglected Tropical Disease. https://doi.org/10.1371/journal.pntd.0001621

[11] UNICEF (2008) Water Sanitation and Hygiene. UNICEF WASH Strategies Paper. http://www.unicef.org/

[12] Bartram, J. and Cairncross, S. (2010) Hygiene, Sanitation, and Water: Forgotten Foundations of Health. PLoS Medicine, 7, e1000367. https://doi.org/10.1371/journal.pmed.1000367

[13] Ekpo, U.F., Odoemene, S.N., Mafiana, C.F. and Sam-Wobo, S.O. (2008) Helminthiasis and Hygiene Conditions of Schools in Ikenne, Ogun State Nigeria. PLOS Neglected Tropical Disease, 2, e146. https://doi.org/10.1371/journal.pntd.0000146

[14] Yamane, T. (1967) Statistics: An Introduction to Analysis. 2nd Edition, Harper and Row Publishing House, New York.

[15] Ogunkanbi, A.E. and Sowemimo, O.A. (2014) Factors Associated with Ascariasis among Pre-School Aged Children in Ile-Ife, Osun State Nigeria. Journal of Parasitology and Vector Biology, 6, 117-123.

[16] WHO (2012) Soil-Transmitted Helminthiasis: Eliminating Soil-Transmitted Helminthiasis as a Public Health Problem in Children: Progress Report 2001-2010 and Strategic Plan 2011-2020. World Health Organisation, Geneva.

[17] Anderson, R.M., Turner, H.C., Truscott, J.E., Hollingsworth, T.D. and Brooker, S.J. (2015) Should the Goal for the Treatment of Soil Transmitted Helminth (STH) Infections Be Changed from Morbidity Control in children to Community-Wide Transmission Elimination? PLoS Neglected Tropical Diseases, 9, e00003897. https://doi.org/10.1371/journal.pntd.0003897

[18] Strunz, E.C., Addiss, D.G., Stocks, M.E., Ogden, S., Utzinger, J. and Freeman, M.C. (2014) Water, Sanitation, Hygiene and Soil-Transmitted Helminth Infection: A Systematic Review and Meta-Analysis. PLoS Medicine, 11, e1001620. https://doi.org/10.1371/journal.pmed.1001620

[19] Acka, C.A., Raso, G., N’Goran, E.K., Tschannen, A.B., Bogoch, I.I., Seraphin, E., Tanner, M., Obrist, B. and Utzinger, J. (2010) Parasitic Worms: Knowledge, Attitude, and Practices in Western Cote d'Ivoire with Implication for Integrated Control. PLoS Neglected Tropical Diseases, 4, e910. https://doi.org/10.1371/journal.pntd.0000910

[20] Mcmanus, D.P., Bieri, F.A., Li, Y., Williams, G.M., Yuan, L., Henglin, Y., Du, Z., Clements, A.C.A., Steinmann, P., Raso, G., Yap, P., Soares Magalhaes, R.J., Stewart, D., Ross, A.G., Halton, K., Zhou, X., Olveda, R.M., Tallo, V. and Gray, D.J. (2014) Health Education and the Control of Intestinal Worm Infections in China: A New Vision. Parasites and Vectors, 7, 344-346. https://doi.org/10.1186/1756-3305-7-344

[21] Xuan, L.T., Hoat, L.N., Rheinlander, T., Dalsgaard, A. and Konradsen, F. (2012) 
Sanitation Behavior among Schoolchildren in a Multi-Ethnic Area of Northern Rural Vietnam. BMC Public Health, 12, 140. https://doi.org/10.1186/1471-2458-12-140

[22] Adefioye, O.A., Efunshile, A.M., Ojurongbe, O., Akindele, A.A., Adewuyi, I.K., Bolaji, O.S., Adedokun, S.A. and Adeyeba, A.O. (2011) Intestinal Helminthiasis among School Children in Illie, Osun State, Southwest Nigeria. Sierra Leone Journal of Biomedical Research, 3, 36-42. https://doi.org/10.4314/sljbr.v3i1.66651

[23] Sam-Wobo, S.O., Mafiana, C.F. and Amusan, A.A.S. (2005) Health Knowledge and Hygiene Behaviours among School Children in Relation to Ascariasis in Ogun State, Nigeria. Tanzania Health Research Bulletin, 7, 62-66.

[24] Mascarini-Serra, L. (2011) Prevention of Soil Transmitted Helminth Infections. Journal of Global Infectious Diseases, 3, 175-182.

https://doi.org/10.4103/0974-777X.81696

Submit or recommend next manuscript to SCIRP and we will provide best service for you:

Accepting pre-submission inquiries through Email, Facebook, LinkedIn, Twitter, etc. A wide selection of journals (inclusive of 9 subjects, more than 200 journals)

Providing 24-hour high-quality service

User-friendly online submission system

Fair and swift peer-review system

Efficient typesetting and proofreading procedure

Display of the result of downloads and visits, as well as the number of cited articles

Maximum dissemination of your research work

Submit your manuscript at: http://papersubmission.scirp.org/

Or contact jwarp@scirp.org 